\title{
DR. ROBERTO JARAMILLO URICOECHEA
}

\author{
Jorge Gómez Cusnir MD*
}

Constituye un verdadero honor, pero además un reto tratar de resumir en unas breves palabras, lo que representó el profesor Roberto Jaramillo Uricoechea, para la Sociedad de Cirugía de Bogotá-Hospital de San José, para su Departamento de Ginecología y Obstetricia, para la Fundación Universitaria de Ciencias de la Salud y el Hospital Infantil Universitario de San José, y para todos aquellos que tuvimos la fortuna no solo de haber sido sus alumnos, colegas, amigos y familia.

Nació en la ciudad de Bogotá, el 15 de diciembre de 1930, de la familia conformada por don Vespasiano Jaramillo y doña Emma Uricoechea, hogar en el que nacieron también sus hermanos Guillermo, Bernardo, Mercedes y Emma Jaramillo Uricoechea. Fue Bachiller del colegio de San Bartolomé de la Merced y médico Cirujano de la Universidad Nacional de Colombia, hizo su especialidad en Ginecología y Obstetricia en el Hospital de San José, al cual se vinculó desde el inicio de sus actividades profesionales y al cual dedicó toda su vida por lo cual hacer un recuento histórico de la misma y de su obra sería una tarea ardua y extensa por lo prolífera y productivas que fueron sus actividades profesional y académica. Fue nuestro ejemplo y guía no solo en nuestra formación y actividad profesional, sino también el consejero y amigo en muchas de nuestras inquietudes personales, de vida y de familia.

Compartió el consultorio con el doctor Arturo Aparicio Jaramillo en el centro médico de la calle 25 A $\mathrm{N}^{\circ} 13 \mathrm{~A}-35$, uno de los primeros en su género en Bogotá, en donde también tenían su consultorio honorables miembros de la Sociedad de Cirugía de Bogotá; allí conoció a la que posteriormente sería su señora y

* Presidente de la Sociedad de Cirugía, Hospital de San José, Bogotá DC, Colombia. compañera hasta el último de sus días, la señora Alicia Colmenares Valero a quien cariñosamente conocíamos como la "Mona", quien fue su asistente por muchos años en su actividad en el consultorio y cuya partida cambió su vida, su rutina y su dependencia, para dedicarse a consentir a la "Chata”, su hija que lo acompañó toda la vida, a sus hijos y a sus nietos.

El doctor Roberto fue en su vida un ser especial, de esos que dejan huella, un ser humano extraordinario, esposo y padre ejemplar, un abuelo cariñoso y un amigo incondicional, pero ante todo un gran maestro en el estricto sentido de la palabra. Como profesional durante su carrera lo logró todo, recibió todos los honores que merecidamente le ofrecieron los colegas, los amigos y la vida.

Entregó toda su existencia y su servicio con amor, compromiso y responsabilidad a su alma mater la Sociedad de Cirugía de Bogotá - Hospital de San José y en ella sembró el cariño y el respeto en toda la gran familia del Hospital, de la Fundación Universitaria de Ciencias de la Salud y del Hospital Infantil Universitario de San José, cuyo proyecto acompañó con decisión y dedicación hasta sus últimos días.

El profesor Jaramillo como casi todos le llamaban o el Doctor Roberto, tuvo una vida de esas que se dice, vivió en una forma plena y bien vivida, lo logró todo, ocupó las más altas dignidades en las sociedades científicas y asociaciones a que perteneció y las cuales presidió durante varios años. Fue miembro de número de la Academia Nacional de Medicina, a cuyas sesiones no dejo de asistir cada jueves en la tarde hasta los últimos días de su existencia. Alcanzó los más altos cargos directivos en nuestras instituciones, ocupó la Jefatura del Departamento de Ginecología y Obstetricia de nuestro Hospital desde el año de 1976 cuando sucedió al pro- 
fesor Arturo Aparicio Jaramillo, inicialmente como jefe encargado desde 1964 hasta 1970 y luego como jefe del departamento en propiedad hasta 1983 cuando es nombrado el doctor Germán Montoya. Formó cientos de egresados de la especialidad a quienes trasmitió sus conocimientos sin egoísmo alguno, gran maestro de la Ginecología Colombiana y Latinoamericana como se le reconociera en vida, dejando un verdadero legado y escuela en la ginecología y obstetricia de nuestros egresados y sus alumnos para orgullo de la Sociedad de Cirugía de Bogotá-Hospital de San José. Presidió nuestra sociedad entre 1986 y 1990, ocupó la Decanatura de la facultad de Medicina de la FUCS desde sus inicios en 1998, hasta el año 2000, año en el que ocupa la Rectoría acompañando su crecimiento y desarrollo, aportando toda su experiencia académica y buen juicio; participó con entusiasmo en la compra y puesta en marcha del antiguo hospital Lorencita Villegas de Santos, hoy nuestro ya acreditado Hospital Infantil Universitario de San José. Fue parte de la junta directiva de nuestros dos hospitales, a los que dedicó toda su existencia y prolífica producción intelectual, de múltiples artículos, trabajos y capítulos de textos de la especialidad.

También ocupó el cargo de Rector Honorario de la FUCS desde mayo del 2012 hasta la fecha de su partida. Discreta como fue su vida personal, así fue su muerte en la madrugada del sábado 8 del mes de marzo pasado, recibiendo las más grandes satisfacciones en su vida familiar y profesional, recibió los más altos reconocimientos en vida, lo alcanzó todo y logró todo lo que anheló. Me haría interminable si quisiera exaltar solo algunas ejecutorias sobresalientes de su vida y obra, de seguro muchos de sus alumnos comparten conmigo la enorme gratitud hacia el profesor y nuestro padre de especialidad.

A sus hijos María Mercedes, la Chata y Luis Carlos, sus nietas y nietos, nuestros sinceros sentimientos de pesar y condolencias. Tenga usted profesor Roberto, paz en su tumba y la seguridad del deber cumplido, y disfrute de las tertulias académicas con todos sus colegas y amigos que le acompañan con júbilo a la diestra del Señor. Nos deja querido profesor, un enorme vacío en nuestro corazón y en el grupo empresarial de San José que tanto amó, pero seguiremos su ejemplo, compromiso y lealtad, a los valores y principios que pude compartir con usted en estos 14 años en los órganos de dirección de nuestras instituciones.

Adiós querido Maestro, Colega y Amigo.

Que su Luz nos siga acompañando y nos guíe desde la eternidad. 